\title{
Evaluation of destructive processes in FRC composites using time-frequency analysis of AE signals
}

\author{
Aleksandra Krampikowska ${ }^{1}$, Anna Adamczak - Bugno ${ }^{1, *}$ \\ ${ }^{1}$ Kielce University of Technology, Faculty of Civil Engineering and Architecture, Aleja 1000-lecia Państwa Polskiego 7, 25-314 Kielce, \\ Poland
}

\begin{abstract}
Modern fiber-cement boards currently used in construction are made of natural raw materials such as cement, cellulose fibers and of polyvinyl alcohol (PVA) and water. They replaced the eternitic plates, which were harmful to health, originated by Ludwig Hatschek. Materials made of fiber-cement are used in construction industry as a building and finishing material for facades, internal walls and roofs. Therefore, they are exposed to environmental conditions including rainfall and temperature changes, and in particular to frequent temperature transition through $0^{\circ} \mathrm{C}$ in a 24-hour cycle (cyclic freezingthawing). In addition, fibrous cement materials, primarily used as cladding elements, are exposed to exceptional conditions, which include the high temperature caused by fire.

The article presents the results of experimental tests of flexural strength of cement - fiber boards subjected to exceptional conditions, to which the operation of fire belongs. The paper also presents a proposal to use a non-destructive method of acoustic emission based on time-frequency analysis for testing fiber-cement boards. Interesting research results were obtained that allowed to trace the differences in the mechanisms of material destruction under the influence of the changing time of external factors.
\end{abstract}

\section{Introduction}

Fiber cement or fibrocement (Latin: fibro - fiber, and caementum - cement) is a building material consisting of cement or calcium silicate and mineral fillers, reinforced with fibers (accidentally dispersed or continuous weaves) and tapes or nets and fabrics). Fiber cement boards are characterized by high mechanical strength (minimum bending strength of flat facade fiber cement boards is $4 \mathrm{MPa}$ ), flexibility and durability $[1,2]$.

Modern fiber cement products are harmless to human health. In most cases, the fiber cement linings are resistant to corrosion, rot, fungal growth, and are also resistant to UV.

Pressing and autoclaves are used for the production of fiber cement boards. The pressing pressure is approx. $6,5 \mathrm{~N} / \mathrm{mm}^{2}$. After the compaction cycle, the boards undergo a hardening stage within 6-8 hours, and then they are placed in autoclaves where, at high temperature of $175^{\circ} \mathrm{C}$ and 10 atmospheres, they finally harden. Thanks to this technology, fiber cement boards are characterized by high mechanical strength, and resistance to bending. Some manufacturers of fiber cement linings use recycled materials during production.

Linings made of fiber cement can be given a variety of looks due to the almost unlimited possibilities in the selection of color, textures, dimensions. This circumstance, together with the technical and functional properties, makes the fiber cement claddings for ventilated facades immune to limitations resulting from regional architectural traditions, climatic conditions and the destination of the building. Fiber cement linings can be colored in the mass, they can be made with an external texture layer (imitating wood, stone), they can be painted after installation or even plastered. As a result, ventilated facades with fiber cement linings can be found on newly erected and reconstructed buildings of any type and destination (multi-family and single-family residential, office, industrial, hospitals, etc.). Used fiber cement linings can be recycled [3].

However, the impact of environmental factors such as temperature changes, rainfall, snow, etc. can cause product aging and micro cracks. It is therefore important to determine how the production and operating losses affect the planned functionality and durability of fiber cement based products. Currently carried out material tests of fiber cement boards concerned mainly the determination of standard physical and mechanical parameters in newly produced materials. There are no studies considering the influence of time on the strength of these elements. This is probably due to the fact that this material in its current form has been used in construction relatively recently. What is important, however, is the fact that the exposure of the calcium phases of the cement matrix to the impact of carbon dioxide causes matrix carbonation. In the initial stage of the work of materials, this phenomenon has a positive effect on the material - there is an improvement in the quality of bonding between

\footnotetext{
* Corresponding author: aadamczak@tu.kielce.pl
} 
the layers of material. After only a few years, the degree between the layered bonds begins to decrease due to the stresses caused by temperature and moisture. Although, initial carbonization positively affects the interfacial connection, the reactions of carbon with hydration products contribute to the increase of moisture movement in the material, which ultimately results in the stratification of the matrix. This is obviously a long-term process. However, its effect is a half-way reduction in the strength of the material after 10 years of exposure to the environment $[4,5]$.

Fiber cement boards available on the market are manufactured with two main types of external surfaces. They may have a structure of raw fiber cement or be covered with layers of acrylic coatings. However, even if additional protective coatings are used, there is a risk of exposing the matrix and fibers to external conditions. If the board is incorrectly installed on the grate, the boards are easily damaged by visible chips on their surface. Rarely, however, attention is paid to thoroughly prying the discovered places, which creates the pathways of moisture penetration and damage caused by recurring freezing and thawing. Although these are small areas, unprotected surfaces can significantly reduce the overall durability of the material even in the absence of extreme moisture or other harmful factors [6].

It should also be noted that fibrous cement materials, primarily used as cladding elements, are exposed to exceptional conditions, which include the high temperature caused by fire.

In the literature one can meet the results of tests carried out on fibrous cement elements using nondestructive methods, e.g. ultrasound method. It is therefore reasonable to use a different non-destructive testing method in order to get to know the problem more widely and compare the obtained results. Such a comparison allows to determine which NDT test techniques will confirm the results and validity of their use. For testing materials, including composite materials, the acoustic emission method and methods based on time-frequency spectrum analysis are useful [7-9].

The authors present the possibility of using the acoustic emission method and time frequency analysis as tools for the assessment of the state of cement and fibrous boards.

\section{Materials and methods}

The aim of the research was to compare the differences in the mechanisms of destruction of cement-fiber boards in the dry state and subjected to direct fire. The tests included sample preparation and then a three-point bending test together with acquisition of acoustic emission signals. The next stage of the work was to compare the recorded descriptors for individual samples and analysis of signals in the time-frequency domain.

\subsection{Materials}

Three series of fibrous cement materials marked with the letters PZBS (marked in the further part of the article as A), PZBP25 (marked in the further part of the article as B) and PZBP75 (marked in the further part of the article as C) were tested. The tested samples were cut from a cement fiber board available on the market with dimensions of $3.1 \times 1.25 \mathrm{~m}$. The dimensions of the tested elements were $300 \times 50 \times 8 \mathrm{~mm}$. Each series of tests included 3 samples. Samples A were in an air-dry state. Samples $\mathrm{B}$ before the test were subjected to a flame of a gas burner for 2.5 minutes. Samples $C$ were incinerated with a torch for 7.5 minutes. Table 1 presents basic data on the tested samples.

Table 1. Comparison of tested boards.

\begin{tabular}{|c|c|}
\hline Properties & $\begin{array}{c}\text { Values for } \\
\text { samples from series } \mathbf{A} / \mathbf{B} / \mathbf{C}\end{array}$ \\
\hline $\begin{array}{c}\text { Density } \\
{[\mathrm{g} / \mathrm{cm} 3]}\end{array}$ & $>1,6524$ \\
\hline $\begin{array}{c}\text { Porosity } \\
{[\%]}\end{array}$ & $>18$ \\
\hline Thermal properties & $\begin{array}{c}\text { No danger of ignition or spread } \\
\text { of fire }\end{array}$ \\
\hline Way of application & $\begin{array}{c}\text { Elevation: external wall } \\
\text { cladding, balcony panels, } \\
\text { railings, balustrades }\end{array}$ \\
\hline
\end{tabular}

Three-point bending tests were carried out at the Kielce University of Technology with the use of the Zwick-Roell testing machine. The bending speed was $0.1 \mathrm{~mm} / \mathrm{min}$.

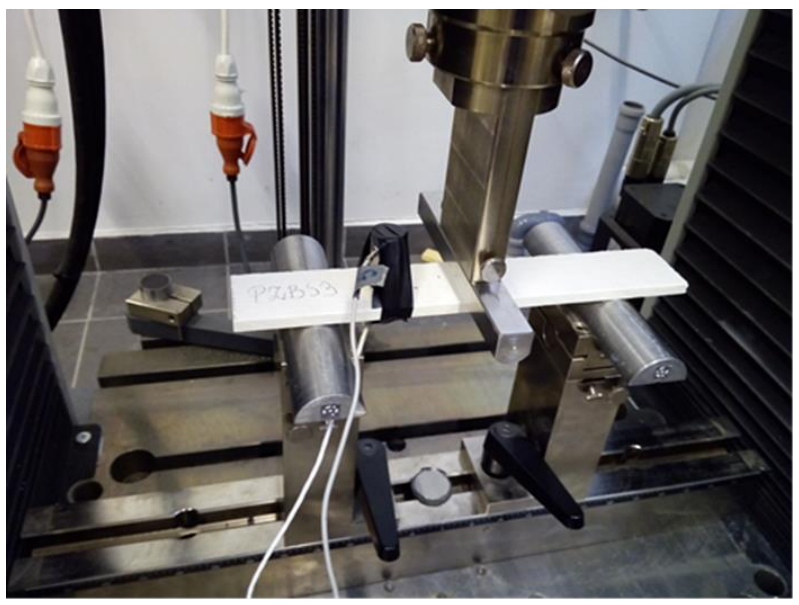

Fig. 1. View of the test bench. 
Fig. 2-4 shows the views of the tested samples after the test.

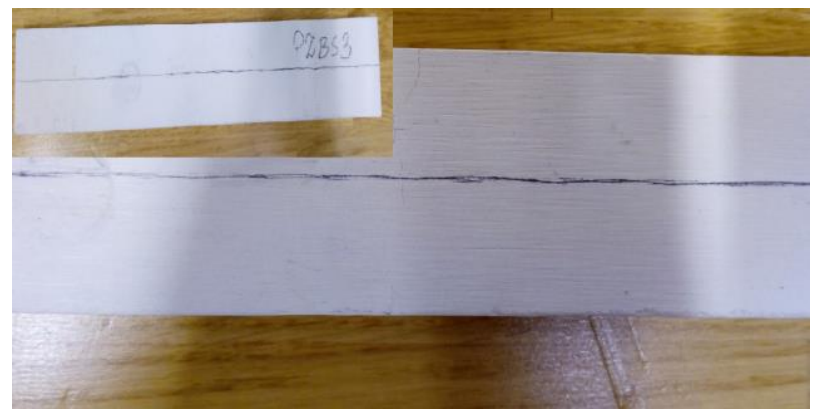

Fig. 2. View of the tested the A sample after destruction.

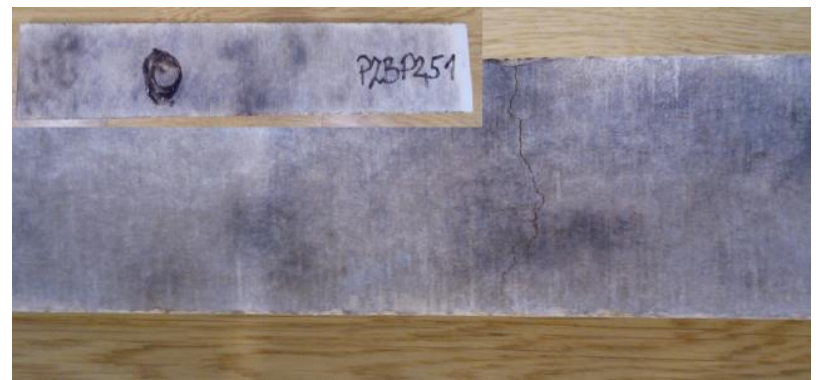

Fig. 3. View of the tested the B sample after destruction.

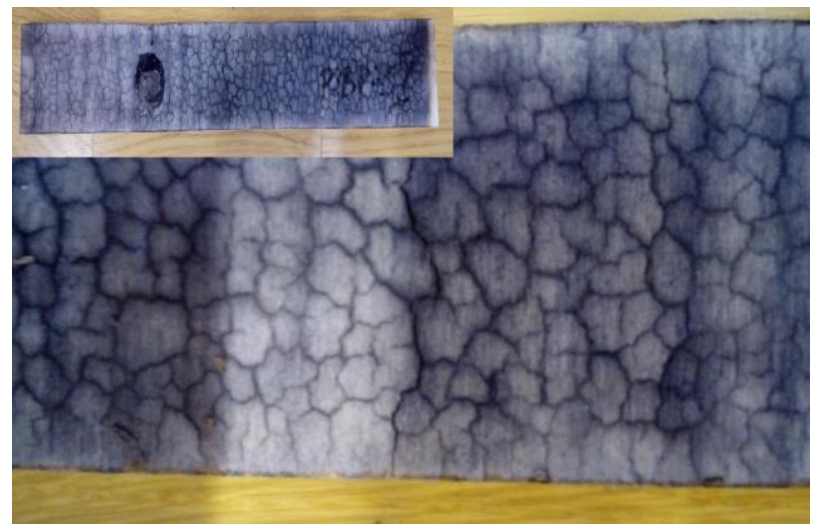

Fig. 4. View of the tested the $\mathrm{C}$ sample after destruction.

Acquisition of acoustic emission signals (AE) during bending tests was carried out using the Vallen AMSY-5 type set. Two broadband sensors were fitted with a clamp in the middle of the sample. A coupling resin layer was applied on the contact surface.

\subsection{Methods}

One of the specific phenomena that occur during bending in materials is the elastic wave, which is identified by an acoustic emission signal with a frequency above $20 \mathrm{~Hz}$. Using diagnostic systems, a signal is obtained from processes occurring during destruction. It is important to characterize this signal, because it has very important information about the destruction process. Proper selection of the signal transformation allows the extraction of a lot of relevant information from the raw signal. The $\mathrm{AE}$ signal is a function of independent variables, containing information about the process. The signal characteristics are represented by amplitude and by frequency. The shape of the signal is called the waveform. The signals are divided into determinate and indeterminate ones. The determinate (stationary) signal is predictable and periodic and can be described using mathematical functions. The existence of a determinate signal is a theoretical assumption, because in reality there is no pure signal waveform, because noise and interference are always present. Indeterminate signals are undefined/random signals, whose probability can be estimated [10-12].

In order to determine the signal measures, selection of the right fragments of the original signal, called segments is needed. Examples of time domain signal measures are primarily statistical measures: variance, mean value, skewness, kurtosis, torque, crest factor, signal power and energy, RMS (root mean square) and standard deviation. Frequency energy may be a measure in the frequency domain, while timefrequency measures are: number of threshold excesses, percentage of signal stay above the threshold for the specified three different thresholds, signal residence time above a certain threshold and a specific hit time that determines the end of the impact (HDT - hit definition time). The first stage of signal processing is its parameterization. An important element is the extraction of specific signal characteristics (feature extraction), enabling an effective description of its properties. Wavelet analysis is effective for this purpose and allows to use long periods of time when very precise data and low frequency data are needed. It also allows the use of short periods when high-frequency data is needed. The key point of a wavelet analysis is to extract information from the original signal, by distributing this signal into a series of approximations and the distribution of data on different frequency bands. The time and frequency characteristics are preserved. The next step in signal processing is to select several distribution sequences that are appropriate for the application. The frequency of the $\mathrm{AE}$ signal is above the audible limit (> $20 \mathrm{kHz})$ [13-16].

\section{Results and discussions}

During the tests of acoustic emission generated during the three-point bending test carried out on the test stand, a number of parameters were registered, which than were analyzed. These parameters include: maximum force, number of events, signal energy. The analysis of these quantities was carried out using the Vallen Visual AE program. The characteristics are shown in Tables 2-4. 
Table 2. The characteristics of AE signals for each dry sample.

\begin{tabular}{|c|c|c|c|}
\hline $\begin{array}{c}\text { Symbol of } \\
\text { board }\end{array}$ & A1 & A2 & A3 \\
\hline $\begin{array}{c}\text { Maximal } \\
\text { load } \\
{[\mathrm{kN}]}\end{array}$ & 0.261 & 0.261 & 0.267 \\
\hline $\begin{array}{c}\text { Total } \\
\text { number of } \\
\text { AE counts }\end{array}$ & 206 & 526 & 577 \\
\hline $\begin{array}{c}\text { Maximal } \\
\text { energy of AE } \\
\text { events } \\
{[\text { eu] }}\end{array}$ & 679452 & 1094933 & 1260601 \\
\hline
\end{tabular}

Table 3. The characteristics of AE signals for each sample flamed for $2,5 \mathrm{~min}$.

\begin{tabular}{|c|c|c|c|}
\hline $\begin{array}{c}\text { Symbol of } \\
\text { board }\end{array}$ & B1 & B2 & B3 \\
\hline $\begin{array}{c}\text { Maximal } \\
\text { load } \\
{[\mathbf{k N ]}}\end{array}$ & 0.201 & 0.224 & 0.224 \\
\hline $\begin{array}{c}\text { Total } \\
\text { number of } \\
\text { AE counts }\end{array}$ & 120 & 154 & 169 \\
\hline $\begin{array}{c}\text { Maximal } \\
\text { energy of AE } \\
\text { events } \\
\text { [eu] }\end{array}$ & 840333 & 2033670 & 2089901 \\
\hline \begin{tabular}{c} 
\\
\hline
\end{tabular}
\end{tabular}

Table 4. The characteristics of AE signals for each sample flamed for 7,5 $\mathrm{min}$.

\begin{tabular}{|c|c|c|c|}
\hline $\begin{array}{c}\text { Symbol of } \\
\text { board }\end{array}$ & C1 & C2 & C3 \\
\hline $\begin{array}{c}\text { Maximal } \\
\text { load } \\
{[\mathbf{k N ]}}\end{array}$ & 0.117 & 0.166 & 0.158 \\
\hline $\begin{array}{c}\text { Total } \\
\text { number of } \\
\text { AE counts }\end{array}$ & 105 & 516 & 96 \\
\hline $\begin{array}{c}\text { Maximal } \\
\text { energy of AE } \\
\text { events } \\
{[\text { eu] }}\end{array}$ & 684918 & 969976 & 119880 \\
\hline
\end{tabular}

Sample graphs showing the number of events (green line) with a curve of the force increment (red line) and signal energy as a function of time, recorded during the tests, are presented in Figures 5-10.

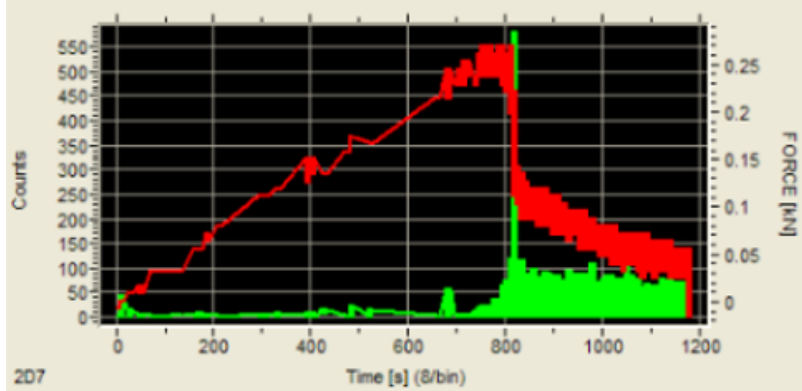

Fig. 5. Record of the number of counts in a function of time with a plot of the force increment for the exemplary sample of the A series.

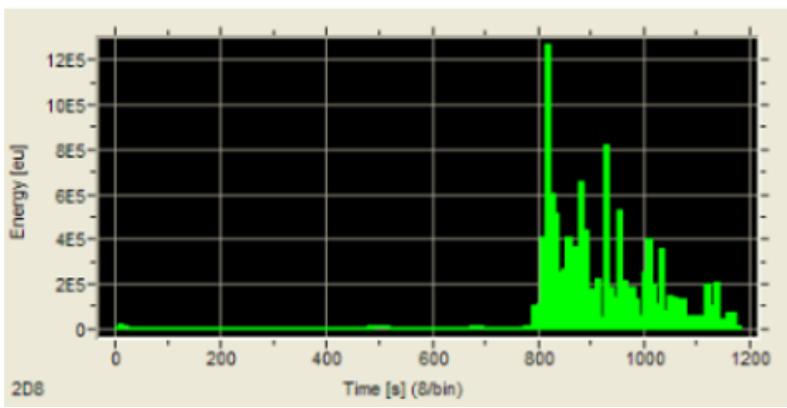

Fig. 6. Graph of signal energy in time for the exemplary sample of the A series.

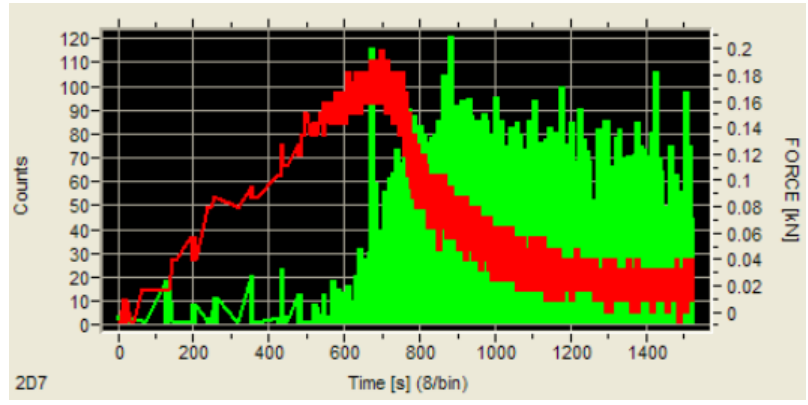

Fig. 7. Record of the number of counts in a function of time with a plot of the force increment for the exemplary sample of the B series.

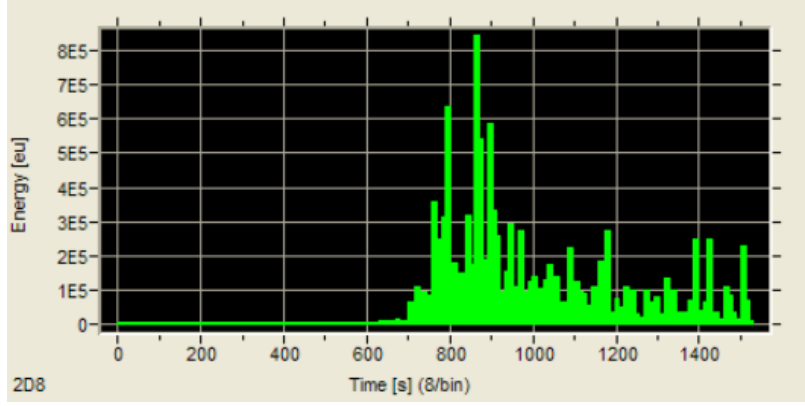

Fig. 8. Graph of signal energy in time for the exemplary sample of the B series. 


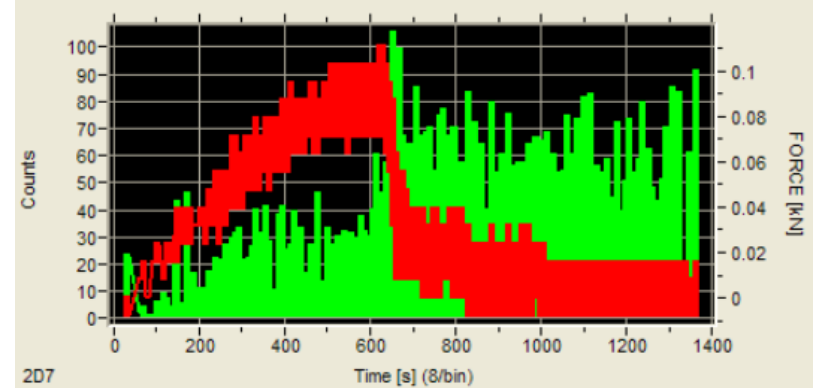

Fig. 9. Record of the number of counts in a function of time with a plot of the force increment for the exemplary sample of the $\mathrm{C}$ series.

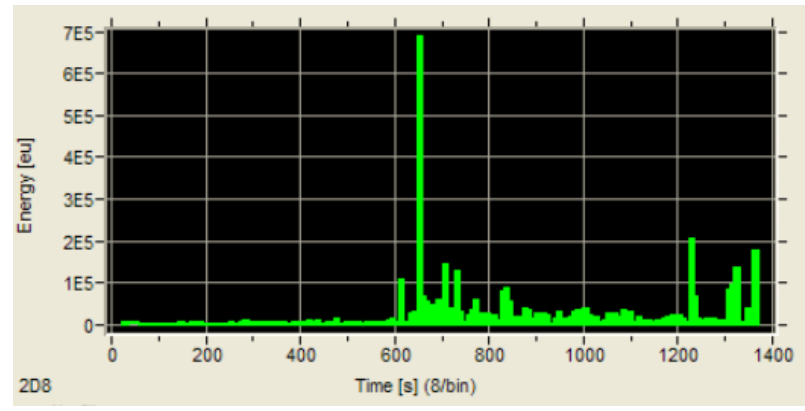

Fig. 10. Graph of signal energy in time for the exemplary sample of the $\mathrm{C}$ series.

Analyzing Tables 2-4 and Figures 5-10, one can observe significant differences in the process of destroying the tested samples. In the case of dry samples, low acoustic activity is observed in almost the entire process. It is only when the sample is destroyed that there is a very significant increase in the number of counts and in the energy of acoustic emission events. AE counts recorded after reaching the maximum load level are not numerous, they do not involve a significant level of signal energy and decrease with time of the test.

Burning samples for 2.5 minutes results mainly in the reduction of the maximum bending force. The difference in the distribution of AE descriptors over time is clearly visible. From the beginning of the analyzed course, the appearing AE counts can be observed before reaching the maximum load value. They do not cause an increase in energy, they were found to be related to the formation of micro cracks in the cement matrix as the load increases. A clear increase in the level of registered descriptors can be observed when the highest load level is reached. The high level of counts is maintained until the end of the analyzed course, but it is not associated with a high level of energy. Looking at the view of the sample after destruction, the high number of counts was related to the cracking of the matrix along the lines in which the flame penetrated the material deepest. The decrease in the overall level of counts compared to an air dry sample was considered due to the fact that some of the fibers were burned out in the stretched sample zone. In the case of sample in air-dry state, a sudden jump in the number of counts was identified with a fiber bundle break.
For the samples burning for 7,5 minutes, a high level of counts can be observed from the beginning of the study. Also in this case, it was identified with the brittle fracture of the matrix in the tensile zone of the samples. Analyzing the condition of the sample after the test, it is clearly visible that the crack runs along the line determined by the action of the fire. A significant decrease in bending force was recorded. Also in this case acoustic activity characterized by a high level of counts is not associated with an increase in energy.

Figures 11-13 show examples of the shapes of the signal generated when the sample was destroyed and their interpretation after the FTT (Fast Fourier Transform) analysis. Using the Vallen wavelet module dedicated to the Vallen AMSY-5 software, the frequency spectrum signal charts for the A sample (Fig. 11), for the B sample (Fig. 12) and for the C sample (Fig. 13) were determined at the time of destruction. Analyzing the presented graphs, it can be observed that in the case of the A sample, peak amplitudes occur for frequencies in the range of $30-750 \mathrm{kHz}$. In the entire analyzed waveform, the signal is characterized by significant jumps in the field of amplitude. However, the values of the amplitudes achieved are not high. This spectrum was classified as induced by breaking the reinforcement. In the case of the $\mathrm{B}$ sample and the $\mathrm{C}$ sample, the signals run more flatly. For a sample $\mathrm{B}$, the range of dominating frequencies was determined in the range of $30-950 \mathrm{kHz}$, while for the $\mathrm{C}$ sample in the range of $30-400 \mathrm{kHz}$.

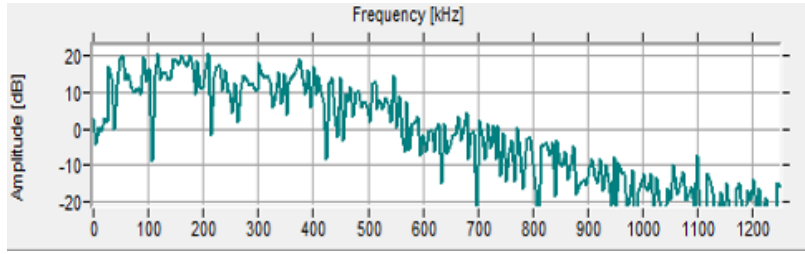

Fig. 11. Frequency spectrum of the sample signal for the A sample.

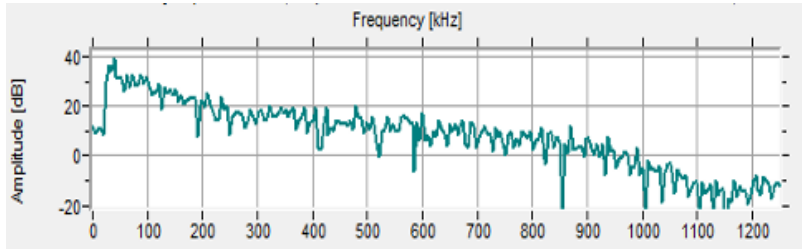

Fig. 12. Frequency spectrum of the sample signal for the B sample.

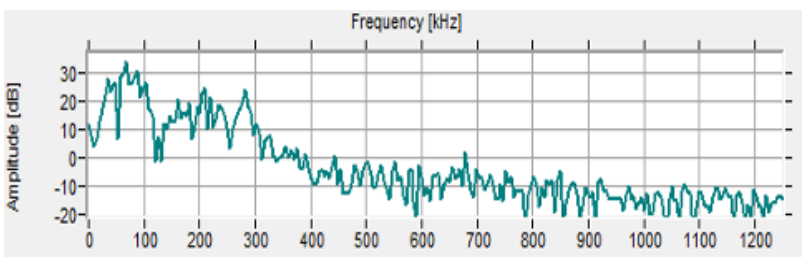

Fig. 13. Frequency spectrum of the sample signal for the $C$ sample. 
The evaluation of the AE signals of the tested boards was also performed in the time-frequency domain, determining the three-dimensional spectrum of the spectral power density. Figures 14-16 present spectrograms of spectral power density of AE signals generated by the tested fiber cement board samples.

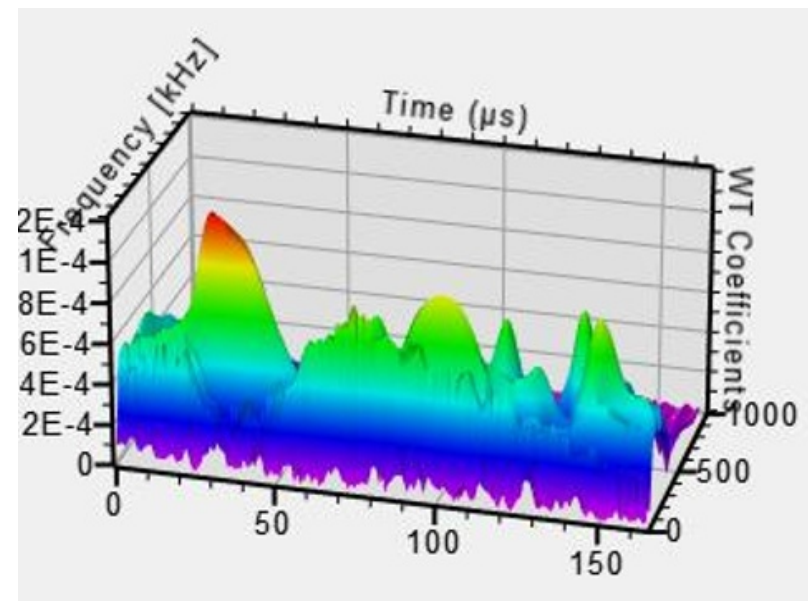

Fig. 14. Three-dimensional spectrograms of spectral density of AE signals generated during bending of the A sample.

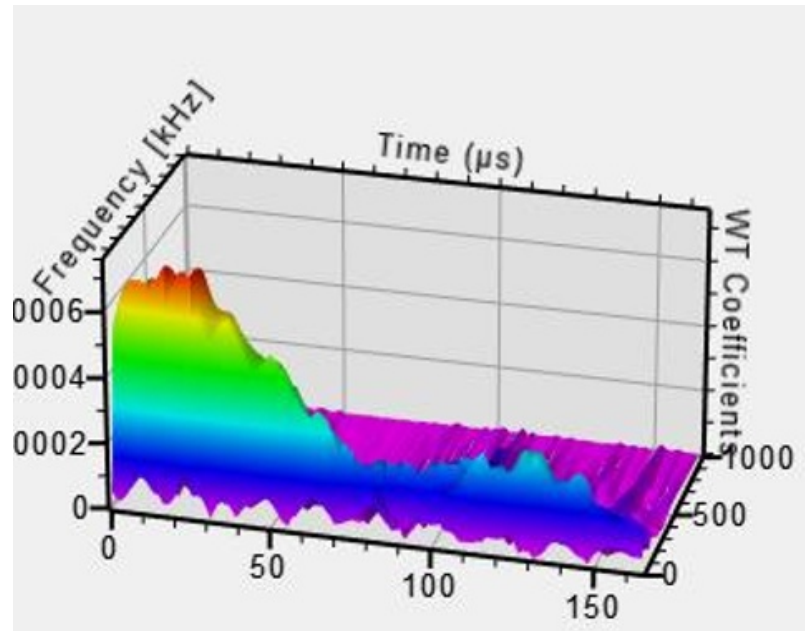

Fig. 15. Three-dimensional spectrograms of spectral density of AE signals generated during bending of the B sample.

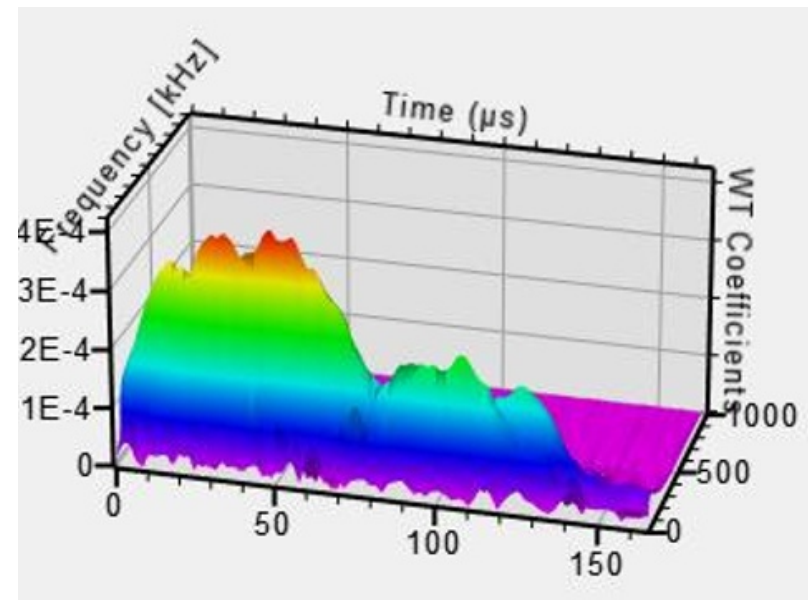

Fig. 16. Three-dimensional spectrograms of spectral density of $\mathrm{AE}$ signals generated during bending of the $\mathrm{C}$ sample.
The presented spectrograms of the spectral power density show time-frequency structures differing in the bands of dominant frequencies. In the case of the $\mathrm{A}$ sample, the band of dominant frequencies is in the range of $30-700 \mathrm{kHz}$ (Figure 14). In the case of the B sample, it is $30-950 \mathrm{kHz}$ (Figure 15). For the $\mathrm{C}$ sample, the band was determined in the range of $30-400 \mathrm{kHz}$ (Figure 16). The largest amplitude values have frequency components in the range from 150 to $250 \mathrm{kHz}$ for the A sample (Figure 14). For the B sample and the C sample the highest amplitude values were observed for frequency components from $50 \mathrm{kHz}$ to $100 \mathrm{kHz}$ (Fig. 15, 16). Based on the analysis of spectrograms determined for $\mathrm{AE}$ signals generated by individual samples, significant differences in their time-frequency structure were found. Significant stratification of the acoustic structure of the analyzed AE signal for the A sample was observed, as well as the different distribution of individual frequency structures over time compared to the remaining samples. In the case the $\mathrm{B}$ sample and the $\mathrm{C}$ sample, the structures are much less delaminated, which was related to the micro-scratch process in the analyzed time.

\section{Conclusions}

The paper presents a proposal for the use of nondestructive acoustic emission method and timefrequency analysis for testing fiber cement boards. The tests were carried out on three series of samples cut from a fiber cement board available on the market. The obtained results allowed to observe changes occurring in the material under the influence of load. The method showed the applicability in the construction practice. Therefore, it should be further developed to diagnose fibrous cement materials.

\section{References} http://www.euronit.de/

2. Information from the website: http://www.cembrit.com/

3. A. M.Cooke, 7th Inorganic-Bonded Wood and Fiber Conference (2000)

4. T. Gorzelańczyk, K. Schabowicz, M. Szymków, Welding Technology Review (in Polish) 88 (10), 2016

5. T. Gorzelańczyk, K. Schabowicz, 11th European Conference on Non-Destructive Testing (2014)

6. D. G. Aggelis, Mechanics Research Communications 38 (3), (2011)

7. D. G. Aggelis, D. V. Soulioti, N. Sapouridis, N. M. Barkoula, A.S. Paipetis, T. E. Matikas, Construction and Building Materials 25 (11), (2011)

8. M. Ardanuy, J. Claramunt, R. D. Toledo Filho, Construction and Building Materials 79, (2015)

9. Y. Chen, D. Bloomquist, R. Crowley, Applied Mechanics and Materials, 239-240 (2013) 
10. B. Goszczyńska, G. Świt, W. Trąmpczyński, Bulletin of the Polish Academy of Sciences: Technical Sciences 63 (1), (2015)

11. G. Świt, P. Olaszek, J. Casas, Bridge Maintenance, Safety, Management And Life-Cycle Optimization (2010)

12. G. Świt, Journal of Materials in Civil Engineering 16 (5), (2004)

13. P. Olaszek, G. Świt, J. R. Casas, Proceedings of the Institution of Civil Engineers - Bridge Engineering 169 (2), (2016)

14. G. Świt, A. Adamczak, A. Krampikowska, IOP Conf. Series: Materials Science and Engineering 245 (2017)

15. G. Świt, A. Adamczak, A. Krampikowska, IOP Conference Series: Materials Science and Engineering 251 (2017)

16. G. Świt, A. Krampikowska, 2016 Prognostics and System Health Management Conference (PhmChengdu) (2016) 